\title{
BMJ Open Gender difference in unmet need for assistance with activities of daily living among disabled seniors in China : a cross-sectional study
}

\author{
Na Chen (D) , ${ }^{1}$ Xin Li (D) , ${ }^{2}$ Min Deng, ${ }^{1}$ Chang Qing Wang, ${ }^{3}$ Chengchao Zhou (D) ${ }^{4}$
}

To cite: Chen N, Li X, Deng M, et al. Gender difference in unmet need for assistance with activities of daily living among disabled seniors in China : a cross-sectional study. BMJ Open 2021;11:e044807. doi:10.1136/ bmjopen-2020-044807

- Prepublication history for this paper is available online. To view these files, please visit the journal online (http://dx.doi. org/10.1136/bmjopen-2020044807).

Received 15 September 2020 Accepted 23 May 2021

Check for updates

(C) Author(s) (or their employer(s)) 2021. Re-use permitted under CC BY-NC. No commercial re-use. See rights and permissions. Published by BMJ.

${ }^{1}$ School of Health Economics and Management, Nanjing University of Traditional Chinese Medicine, Nanjing, Jiangsu,

China

${ }^{2}$ School of Pharmacy, Nanjing Medical University, Nanjing, Jiangsu, China

${ }^{3}$ Nanjing Medical University, Nanjing, Jiangsu, China

${ }^{4}$ School of Public Health, Shandong University, Jinan, Shandong, China

\section{Correspondence to}

Dr Na Chen;

chenna@njucm.edu.cn and

Professor Chengchao Zhou;

zhouchengchao@sdu.edu.cn

\section{ABSTRACT}

Objectives This study explores the gender difference in unmet need for assistance with activities of daily living among older adults with disabilities in China.

Design Logistic regression analysis was employed to examine the gender difference and identify influential factors among disabled male and female seniors.

Setting 23 provinces throughout China.

Participants A total of 1700 disabled seniors were included in the analysis.

Results Of 1700 respondents, 619 (36.4\%) were disabled male seniors. Overall, the possibility of unmet need for activity of daily living assistance among disabled female seniors was significantly lower than that among male group (OR $0.728 ; 95 \% \mathrm{Cl} 0.559$ to 0.948 ) than males. Family care resources, economic status and loneliness were influential factors among disabled seniors regardless of genders. Furthermore, disabled female seniors from rural area $(p=0.011)$, whose primary caregiver was willing to take care of them $(p=0.022)$, whose community could provide daily life service $(p=0.002)$ were more likely to have unmet need. Meanwhile, disabled female seniors whose community could provide medical service $(p=0.001)$ were less likely to report unmet need.

Conclusions The study showed that disabled male seniors were more likely to experience unmet need compared with female ones. Reducing unmet need for assistance with activities of daily living among disabled seniors and existing gender disparities therefore requires not only universal strategy, but also targeted policies which should be made or modified for disabled seniors of different genders.

\section{INTRODUCTION}

Unmet need for assistance with activity of daily living (ADL), which occurs when assistance is insufficient or unavailable to satisfy needs to complete an ADL task, ${ }^{1}$ has been considered as one indicator of long-term care ${ }^{2}$ and quality of life ${ }^{3}$ in many studies. Unmet need for ADL assistance is always related to heavy psychological stress, ${ }^{4}$ more hospitalisations or hospital readmissions ${ }^{5}$ and higher mortality rate. $^{16}$
Strengths and limitation of this study

- The study attempts to explore the disparity of unmet need for activity of daily living (ADL) assistance and influential factors between male and female disabled seniors, which has not been studied in China.

- A large sample of 1700 respondents from 23 provinces throughout China provides a real state of unmet need for ADL assistance among disabled seniors, which are the more vulnerable part of the population.

- Some self-reported information may lead to the possibility of bias.

The cross-sectional design precludes any causality.

With the coming of ageing society, the proportion of seniors living with disabilities will be on the rise as a result of longer lifespans and wide spread of chronic diseases. ${ }^{7-9}$ Due to the deterioration of physical functions and chronic diseases, the probability of suffering from unmet need for assistance with ADL among disabled seniors is significantly higher than others. ${ }^{10}$ Accordingly, more and more long-term care, which refer to services provided by formal or informal caregivers to ensure the quality of life and functional ability, ${ }^{6}$ are needed to meet the surge in demand of assistance with ADL. Consequently, the issue of unmet need is considered as a priority for global research in geriatrics, especially for disabled seniors. Understanding influential factors of unmet need for ADL assistance is not only vital for optimising long-term care policy, but also essential to improve efficiency and outcome of health service.

Previous studies have identified influential factors related to unmet need for ADL assistance, such as socioeconomic status, ${ }^{6} 1112$ living arrangement, ${ }^{6}{ }^{11}$ non-communicable diseases (NCDs), ${ }^{3}$ social support ${ }^{13}$ and number of ADL difficulties. ${ }^{11} 13$ 
Furthermore, there are many evidences certificated that gender is a significant influential factor of unmet need for ADL assistance in developed countries. ${ }^{14}$ However, little studies have investigated the unmet need for ADL assistance in low/middle-income countries, ${ }^{12}$ especially among disabled seniors. Even less studies focus on gender difference where there are great disparities existing in physical-mental health-related quality of life, ${ }^{15}$ attachment patterns and relational self-construal ${ }^{16}$ among Chinese disabled seniors. To the best of our knowledge, none study analysis whether influential factors of unmet need for ADL assistance are similar between disabled male and female seniors in China.

Given unmet need as a significant factor affecting longterm care and quality of life, it is an important gerontological research field. There are few studies on gender difference in unmet need for ADL assistance among the disabled elderly in developed countries, our study aims to investigate gender difference and identify influential factors associated with unmet need for ADL assistance in female and male disabled seniors in China with a relatively large sample.

\section{METHODS}

\section{Survey design}

Data were drawn from the most recent wave of the Chinese Longitudinal Healthy Longevity Survey (CLHLS) in 2014, which was proved to be of good quality. ${ }^{17}$ The CLHLS was conducted in half of the cities/counties in 23 provinces throughout China and followed up every 3 years since 1998. Most importantly, it was the only national survey that collects unmet need for ADL assistance as an important index in China.

We focused our analysis on disabled seniors who had difficulty in performing at least one of the following six ADLs measured by Katz Activity of Daily Living Scale, ${ }^{18} 19$ including feeding, dressing, bathing, toileting, walking inside, bladder and bowel control. Consequently, 1700 disabled seniors were drawn from 7192 subjects in the 2014 wave of CLHLS, which included 619 males and 1081 females.

\section{Variables and measures}

Dependent variable

The dependent variable was unmet need for ADL assistance, which was considered as the presence of any unavailable need for ADL assistance, measuring by the question, 'Does the assistance meet your needs?' There were three possible answers: (1) not met, (2) partially met and (3) fully met. Based on the practice of previous researches, ${ }^{2} 6$ we divided responses into two categories: (1) met need (answered 'fully met') and (2) unmet need (answered 'partially met' or 'not met').

\section{Independent variables}

As guided by Andersen-Nyman model, ${ }^{20}{ }^{21}$ we classified explanatory factors into three categories: (1) Predisposing variables, including gender (male, female), age (60-74, $75-89,90+$ ), marital status (couple or single) and education (illiterate or literate); (2) Enabling variables, including residence (rural or urban), living arrangements (living with children or others, living alone) and household income (Q1, Q2 andQ3). Quartile 1 (Q1) is the poorest and quartile 3 (Q3) is the richest; (3) Need variables, including no of NCDs $(0,1$ or $2+)$, no of ADL disability (1-2, 3-4, 5-6) and loneliness (often or seldom). Furthermore, we modified the model by adding family factors (family care resources and primary caregiver's willingness) and community factors (community service for health or life) as enabling factors in accordance with China's national context. ${ }^{22}$

\section{Statistical analysis}

Statistical analysis was performed individually among male and female subgroups using statistical package SPSS V.20.0. $\chi^{2}$ test was conducted to examine differences in categorical variables. Logistic regression with an enter method was applied to assess the association of unmet need for ADL assistance with gender, and to identify influential factors for disabled male and female seniors, respectively. All reported CIs were calculated at the 95\% level. Statistical significance was set at the $5 \%$ level.

\section{Patient and public involvement statement}

Neither patients nor the public had roles in the design, collection, analysis, and interpretation of data or in writing the manuscript.

\section{RESULTS}

\section{Basic characteristics of the participants}

Table 1 shows basic characteristics of 1700 samples. The overall proportion of unmet need for ADL assistance among the disabled elderly was $60.6 \%$, within $63.3 \%$ for males and $59.0 \%$ for females, respectively. Generally, majority of disabled seniors were female $(63.6 \%)$, at the ages of $90+(64.3 \%)$, single $(76.9 \%)$, illiterate $(67.6 \%)$, from urban area $(53.1 \%)$, living with children or others $(89.6 \%)$, belonging to the middle class $(70.4 \%)$, having sufficient family care resources $(90.4 \%)$, having primary caregiver who was willing to take care of them (97.5\%), having no community service for daily life (69.4\%), having community medical service $(51.6 \%)$, having difficulties in 1-2 ADL (50.8\%) and often feeling lonely (52.6\%). Furthermore, age $(\mathrm{p}<0.001)$, education $(\mathrm{p}<0.001)$, marital status $(\mathrm{p}<0.001)$, residence $(\mathrm{p}=0.004)$, household income $(\mathrm{p}<0.001)$, family care resources $(\mathrm{p}=0.021)$ and loneliness $(p<0.001)$ were significantly different between disabled male and female seniors.

\section{Association of gender and unmet need for ADL assistance among disabled seniors}

To better understand the association between gender and unmet need for ADL assistance among disabled seniors, we adopted two models in table 2. Results from model 
Table 1 Characteristics by gender among study participants in China, CLHLS 2014

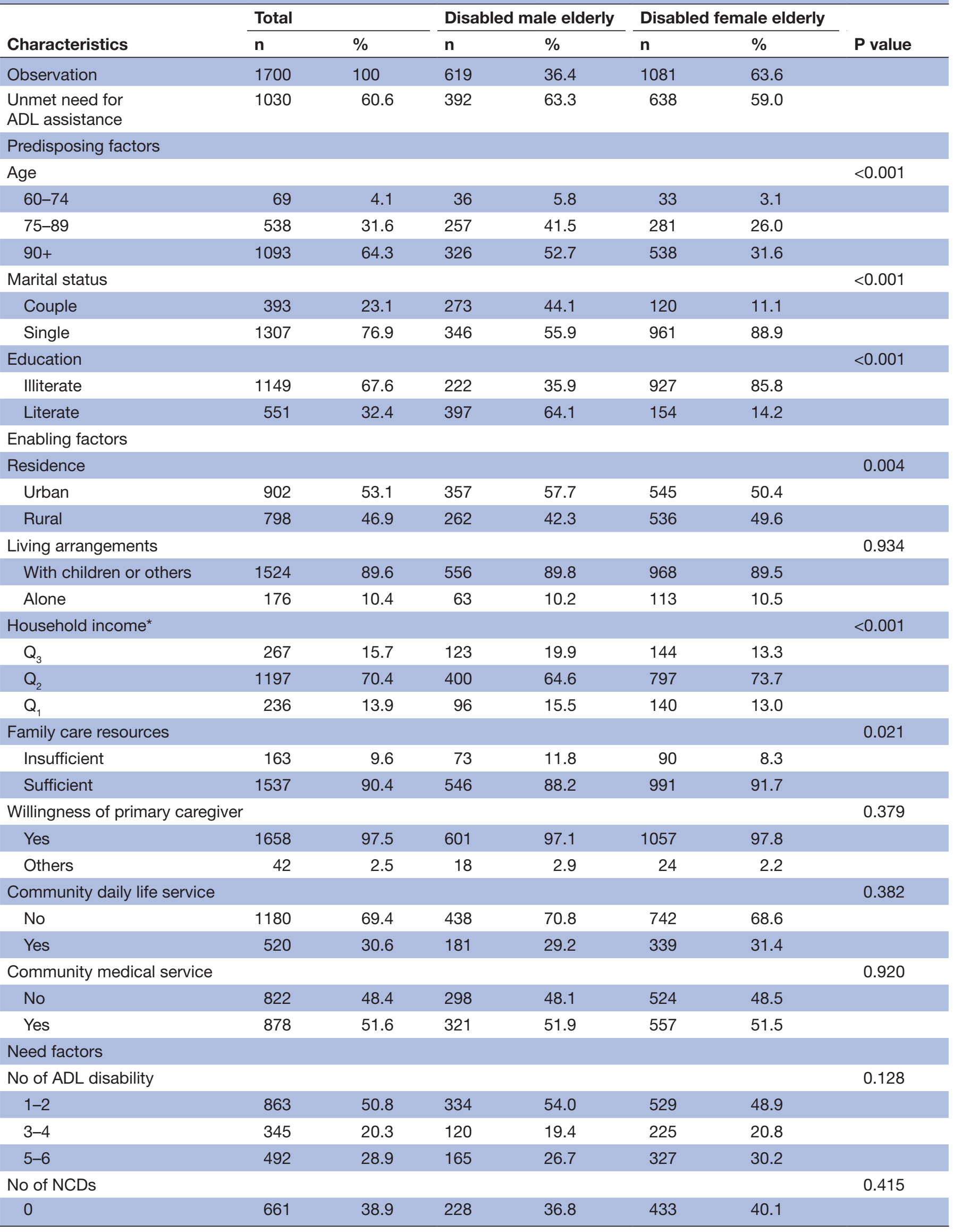


Table 1 Continued

\begin{tabular}{|c|c|c|c|c|c|c|c|}
\hline \multirow[b]{2}{*}{ Characteristics } & \multicolumn{2}{|l|}{ Total } & \multicolumn{2}{|c|}{ Disabled male elderly } & \multicolumn{2}{|c|}{ Disabled female elderly } & \multirow[b]{2}{*}{$P$ value } \\
\hline & $\mathbf{n}$ & $\%$ & $\mathbf{n}$ & $\%$ & $\mathbf{n}$ & $\%$ & \\
\hline 1 & 533 & 31.4 & 199 & 32.1 & 334 & 30.9 & \\
\hline $2+$ & 506 & 29.8 & 192 & 31.0 & 314 & 29.0 & \\
\hline Loneliness & & & & & & & $<0.001$ \\
\hline Often & 895 & 52.6 & 289 & 46.7 & 606 & 56.1 & \\
\hline Seldom & 805 & 47.4 & 330 & 53.3 & 475 & 43.9 & \\
\hline
\end{tabular}

${ }^{*}$ Quartile 3 (Q3) is the richest and quartile 1 (Q1) is the poorest.

ADL, activity of daily living; CLHLS, Chinese Longitudinal Healthy Longevity Survey; NCD, non-communicable disease.

1 indicated that the possibility of unmet need for ADL assistance among disabled female seniors was significantly lower than that among male group $(\mathrm{OR}=0.834$, $95 \mathrm{CI}$ 0.680 to $1.022, \mathrm{p}=0.049$ ). Model 2 identified that when controlling for other variables, the likelihood of unmet need for ADL assistance among the disabled female elderly was still statistically lower than that among male group $(\mathrm{OR}=0.728,95 \mathrm{CI} 0.559$ to $0.948, \mathrm{p}=0.019)$.

\section{Factors associated with unmet need for ADL assistance among disabled male seniors}

Table 3 demonstrates influential factors of unmet need for ADL assistance among disabled male seniors. Univariate analysis showed that the possibility of unmet need among disabled male elders whose household income were corresponding to $\mathrm{Q} 2(\mathrm{p}<0.001)$ or $\mathrm{Q} 1(\mathrm{p}<0.001)$, who had difficulties in 5-6 ADL $(\mathrm{p}<0.001)$ was significantly higher than other subgroups. It also indicated the likelihood of unmet need for ADL assistance among those who had sufficient family care resources $(\mathrm{p}=0.001)$, who seldom felt lonely $(\mathrm{p}<0.001)$ was statistically lower. Multilogistic regression analysis presented that disabled male seniors whose household income were corresponding to Q2 or Q1 were more likely to have unmet need ( $\mathrm{OR}=1.867$ and $\mathrm{OR}=3.891$, respectively). The disabled male elders who had sufficient family care resources and who seldom felt lonely were less likely to experience unmet need $(\mathrm{OR}=0.333$ and $\mathrm{OR}=0.680$, respectively $)$.

\section{Factors associated with unmet need for ADL assistance among disabled female seniors}

As shown in table 4, univariate analysis indicated that the possibility of unmet need for ADL assistance among those disabled female seniors from rural area $(\mathrm{p}=0.003)$, whose household income were corresponding to $Q 2(p<0.001)$ or $\mathrm{Q} 1(\mathrm{p}<0.001)$, whose primary caregivers were willing to take care of them $(\mathrm{p}=0.010)$, whose community could provide daily life service $(\mathrm{p}=0.024)$, who had difficulties in 5-6 ADL $(\mathrm{p}=0.006)$ were significantly higher than other subgroups. It also demonstrated the possibility of unmet need for ADL assistance among those who had sufficient family care resources $(\mathrm{p}=0.009)$, whose community could provide medical service $(\mathrm{p}=0.005)$, who seldom felt lonely $(\mathrm{p}<0.001)$ might decrease statistically. Multilogistic regression analysis showed that disabled female seniors from rural area, whose household income were corresponding to $\mathrm{Q} 2$ or $\mathrm{Q} 1$, whose primary caregivers were willing to take care of them, whose community could provide daily life service were more likely to have unmet need $(\mathrm{OR}=1.401, \mathrm{OR}=1.891, \mathrm{OR}=4.892, \mathrm{OR}=4.268$ and $\mathrm{OR}=1.605$, respectively). The female group who had sufficient family care resources, whose community could provide medical service, who seldom felt lonely were less likely to report unmet need $(\mathrm{OR}=0.491, \mathrm{OR}=0.630$ and $\mathrm{OR}=0.547$, respectively).

\section{DISCUSSION}

To the best of our knowledge, fewer studies focus on the gender difference in unmet need for ADL assistance among disabled seniors in developed countries. Consistent with other studies, ${ }^{2}{ }^{3}$ the finding showed that there was a significant difference of unmet need between disabled male and female subgroup, which was $63.3 \%$ for males and $59.0 \%$ for females. However, another study ${ }^{14}$ indicated that female seniors were more likely to have unmet need among community-dwelling New Zealanders 75 years and over. The possible explanation may be different respondents and context. The status of ADL among females are better than males in China. ${ }^{23}$ Moreover, females are more likely to take care of others even if they are disabled. ${ }^{24}$ Similarly, the role of female seniors is always connected with caregivers for a long time in China, resulting in lower expectations for caring by others, ${ }^{2}$ as well as less likely to report unmet need for ADL assistance compared with male group.

Our study indicated that family care resources, economic status and loneliness were influential factors of unmet need for disabled seniors regardless of genders. The risk of having unmet need decreased when family care resources was sufficient, which was in agreement with previous studies. ${ }^{2526}$ Family members are still best caregivers because of traditional filial piety and inadequate social care system for disabled seniors in China. ${ }^{2}$ Furthermore, disabled seniors with better economic status, having more access to daily life and medical service, were less likely to experience unmet need for ADL assistance, 
Table 2 Association of gender and unmet need for ADL assistance among disabled seniors in China, CLHLS 2014 ( $\mathrm{n}=1700)$

\begin{tabular}{|c|c|c|c|c|}
\hline \multirow[b]{2}{*}{ Characteristics } & \multicolumn{2}{|l|}{ Model 1 (no covariates) } & \multicolumn{2}{|l|}{ Model 2 (covariates) } \\
\hline & OR $(95 \% \mathrm{Cl})$ & $P$ value & OR (95\% Cl) & $P$ value \\
\hline \multicolumn{5}{|l|}{ Gender } \\
\hline Female & 0.834 (0.680 to 1.022$)$ & 0.049 & 0.728 (0.559 to 0.948$)$ & 0.019 \\
\hline \multicolumn{5}{|l|}{ Age } \\
\hline $60-74$ & & & 1.0 & \\
\hline $90+$ & & & $0.586(0.322$ to 1.064$)$ & 0.079 \\
\hline \multicolumn{5}{|l|}{ Marital status } \\
\hline Couple & & & 1.0 & \\
\hline Single & & & 1.062 (0.785 to 1.437$)$ & 0.694 \\
\hline \multicolumn{5}{|l|}{ Education } \\
\hline Urban & & & 1.0 & \\
\hline Rural & & & 1.181 (0.952 to 1.465$)$ & 0.131 \\
\hline \multicolumn{5}{|l|}{ Living arrangements } \\
\hline With children or others & & & 1.0 & \\
\hline Alone & & & $1.057(0.745$ to 1.502$)$ & 0.755 \\
\hline \multicolumn{5}{|l|}{ Household income ${ }^{*}$} \\
\hline $\mathrm{Q}_{3}$ & & & 1.0 & \\
\hline $\mathrm{Q}_{2}$ & & & 1.867 (1.402 to 2.486$)$ & $<0.001$ \\
\hline$Q_{1}$ & & & 4.426 (2.918 to 6.715$)$ & $<0.001$ \\
\hline \multicolumn{5}{|l|}{ Family care resources } \\
\hline No & & & 1.0 & \\
\hline Yes & & & 1.467 (1.152 to 1.870$)$ & 0.002 \\
\hline \multicolumn{5}{|l|}{ Community medical service } \\
\hline No & & & 1.0 & \\
\hline Yes & & & 0.666 (0.534 to 0.832$)$ & $<0.001$ \\
\hline \multicolumn{5}{|l|}{ No of ADL disability } \\
\hline $1-2$ & & & 1.0 & \\
\hline $3-4$ & & & 1.213 (0.921 to 1.598$)$ & 0.170 \\
\hline $5-6$ & & & 1.277 (0.987 to 1.651$)$ & 0.063 \\
\hline \multicolumn{5}{|l|}{ No of NCDs } \\
\hline 0 & & & 1.0 & \\
\hline 1 & & & 1.001 (0.780 to 1.286$)$ & 0.991 \\
\hline $2+$ & & & 1.065 (0.820 to 1.383$)$ & 0.635 \\
\hline \multicolumn{5}{|l|}{ Loneliness } \\
\hline Often & & & 1.0 & \\
\hline Seldom & & & 0.563 (0.452 to 0.702$)$ & $<0.001$ \\
\hline
\end{tabular}

${ }^{*}$ Quartile $3(\mathrm{Q} 3)$ is the richest and quartile 1 (Q1) is the poorest.

$\mathrm{ADL}$, activity of daily living ; CLHLS, Chinese Longitudinal Healthy Longevity Survey; NCD, non-communicable disease. 
Open access

Table 3 Factors associated with unmet need for ADL assistance among disabled male seniors in China, CLHLS 2014 ( $n=619)$

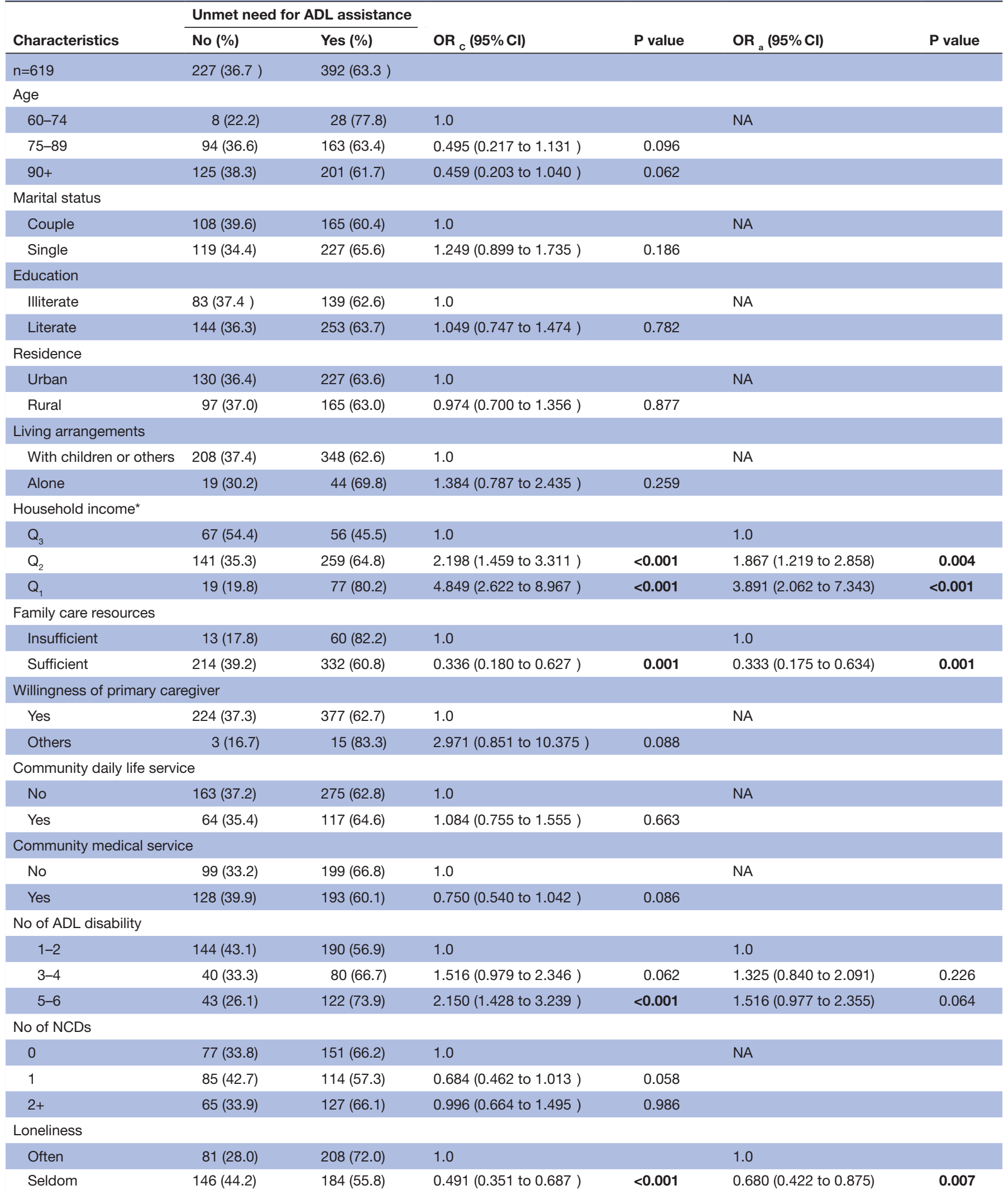

${ }^{*}$ Quartile $3(\mathrm{Q})$ is the richest and quartile 1 (Q1) is the poorest.

ADL, activity of daily living; CLHLS, Chinese Longitudinal Healthy Longevity Survey; NA, not applicable; NCDs, non-communicable diseases; OR adjusted OR; OR , crude OR. 
Table 4 Factors associated with unmet need for ADL assistance among disabled female seniors in China, CLHLS 2014 $(n=1081)$

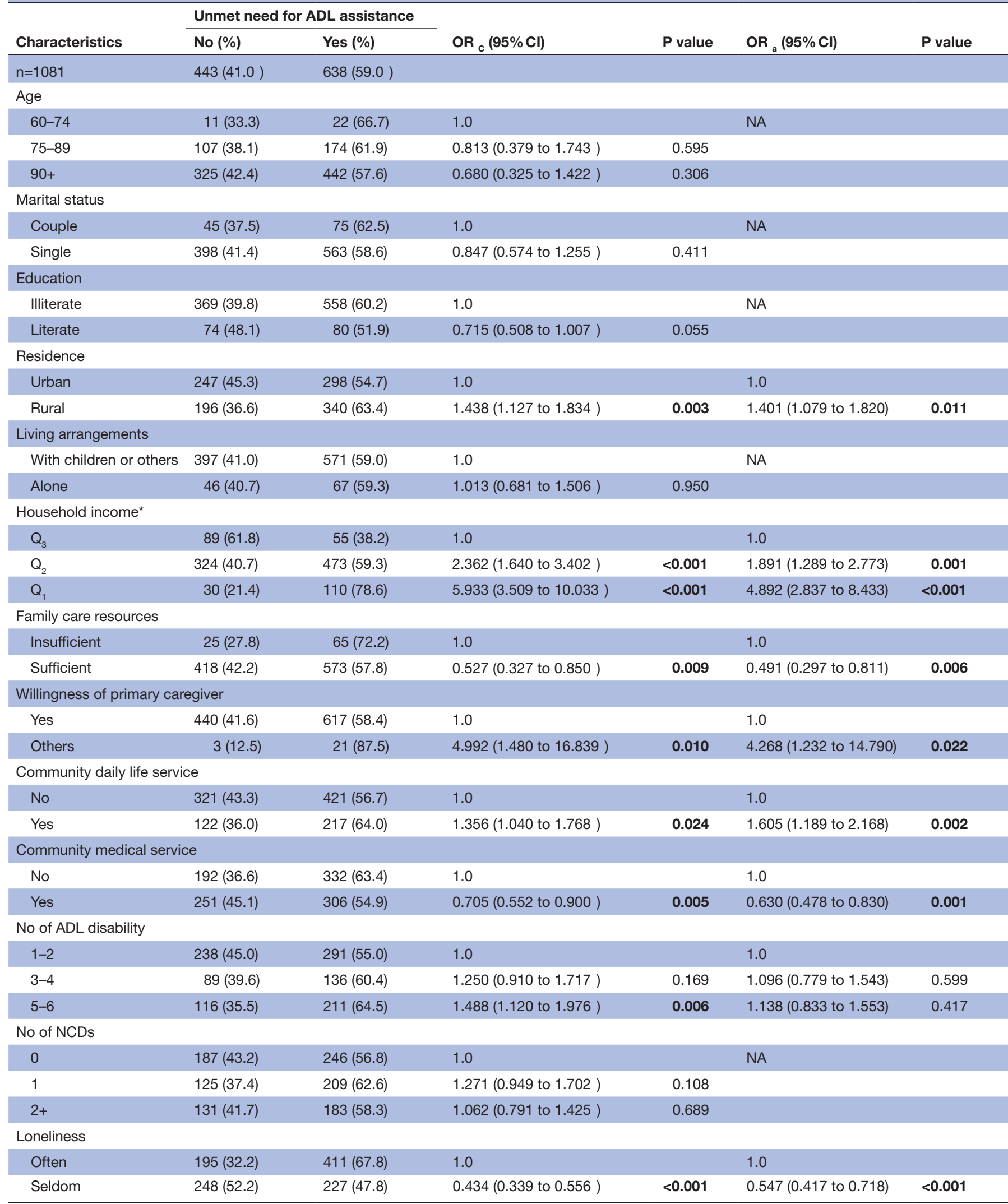

${ }^{*}$ Quartile $3(\mathrm{Q} 3)$ is the richest and Quartile 1 (Q1) is the poorest.

ADL, activity of daily living; CLHLS, Chinese Longitudinal Healthy Longevity Survey; NA, not applicable; NCDs, non-communicable diseases; OR a adjusted OR; OR ${ }_{c}$, crude OR. 
which was in line with previous studies. ${ }^{6}{ }^{25}$ In addition, loneliness was an influential factor to increase the likelihood of experiencing unmet need among disabled seniors, which was also consistent with other studies. ${ }^{27}$ Loneliness is a negative state, expressed as someone perceives herself/himself as socially isolated, which is a risk predictor of malnutrition, ${ }^{28}$ illness in later life ${ }^{29}$ and low satisfaction among seniors in nursing homes. ${ }^{27}$ These findings suggest that targeted policies on ADL assistance should be made for disabled seniors, especially for those who are lonely, with insufficient family care resources or poor economic conditions.

Our results demonstrated that residence, the primary caregiver' s willingness, community daily life and medical service were associated with unmet need for ADL assistance among disabled female but not male seniors. Consistent with previous studies, ${ }^{2}$ rural older females are more likely to experience unmet need compared with urban counterparts. One possible explanation is that socioeconomic status and availability of healthcare service in urban is much better than that in rural areas in China. ${ }^{12}{ }^{30}$ Another explanation may be the strongly entrenched traditional norm of filial piety in the mind of rural female seniors than male ones, ${ }^{2}$ contributing to more dependence on family members, thereby increasing the possibility of unmet need for ADL assistance. The finding indicates that it is imperative to reduce urbanrural socioeconomic differences and renewal conception of pension among rural female seniors.

Parallel to other studies, ${ }^{1325}$ we also found that willingness of primary caregiver and community service influenced the likelihood of unmet need of ADL assistance among disabled female seniors. The willingness of primary caregiver might have an impact not only on quality of caring but also on satisfaction of seniors, ultimately influencing the possibility of reporting unmet need for ADL assistance. Furthermore, many researchers agreed that community service contributed to increasing positive attitudes toward individuals with disabilities. ${ }^{31}$ Furthermore, community service also negatively affects the development of depression in new immigrant women significantly. ${ }^{32}$ In addition, women's unique attachment patterns and relational self-construal ${ }^{16}$ lead to increased sensitivity of primary caregiver's willingness and community service. The finding, therefore, gives an impetus to propose targeted countermeasures, including providing social supports for primary caregivers ${ }^{33}$ and strengthening community medical services for different genders.

Interestingly, community service for daily life didn't decrease the possibility of having unmet need, which was inconsistent with previous study. ${ }^{34}$ The possible reason may be an imbalance status of supply and demand of community service for daily life in China. Online supplemental data analysis indicated that the gap between supply and demand of household care, daily shopping, organising social activity is $51.9 \%$, $46.5 \%, 42.7 \%$, respectively. The finding shows that it is urgent to optimise capabilities of community service for daily life to realise the equilibrium of supply and demand.

This study had several limitations. First, the information of social-demographic characteristics, health status and unmet need were based on self-reported, leading to the possibility of bias. Second, causal relationship cannot be confirmed through cross-sectional studies. Thus, longitudinal researches are required to test whether the link between gender and unmet need for ADL assistance could be cause-and-effect.

\section{CONCLUSION}

This study found that disabled male seniors were more likely to report unmet need for ADL assistance compared with disabled female ones in China. Family care resources, economic status and loneliness were influential factors among disabled seniors regardless of genders. Moreover, residence, willingness of primary caregiver, community daily life and medical service were influential factors of unmet need for ADL assistance among disabled female seniors. Pertinent policies should be made or modified to decreasing the possibility of experiencing unmet need among disabled male and female seniors in a targeted manner.

Contributors All authors contributed to the study conception and design. NC, MD and $\mathrm{XL}$ took part in data collection and statistical analysis. CZ, XL, CQW and NC participated in the interpretation of results. NC and MD drafted the manuscript, $\mathrm{CZ}$ and XL polished it. All authors read and approved the final manuscript.

Funding This study was supported by research grants from Education Ministry of China (Grant Number 20YJC840004), from National Social Science Foundation of China (Grant Number15CRK015) and from National Nature Science Foundation of China (Grant Number 71804076).

Competing interests None declared.

Patient and public involvement Patients and/or the public were not involved in the design, or conduct, or reporting, or dissemination plans of this research.

Patient consent for publication Not required.

Ethics approval The CLHLS study was approved by the research ethics committees of Duke University and Peking University (IRB00001052-13074). Each respondent provided written informed consent before inclusion in the study. In addition, for the respondent who was considered cognitively impaired, the proxy consent procedure would be adopted to ensure high reliability and validity of the data.

Provenance and peer review Not commissioned; externally peer reviewed.

Data availability statement Data are available in a public, open access repository. The datasets used and/or analysed during the current study are available from the https://opendata.pku.edu.cn/dataset.xhtml?persistentld=doi:10.18170/DVN/ XRV2WN. The database is accessible to researchers.

Open access This is an open access article distributed in accordance with the Creative Commons Attribution Non Commercial (CC BY-NC 4.0) license, which permits others to distribute, remix, adapt, build upon this work non-commercially, and license their derivative works on different terms, provided the original work is properly cited, appropriate credit is given, any changes made indicated, and the use is non-commercial. See: http://creativecommons.org/licenses/by-nc/4.0/.

\section{ORCID iDs}

Na Chen http://orcid.org/0000-0002-1829-6802

Xin Li http://orcid.org/0000-0003-3951-8061

Chengchao Zhou http://orcid.org/0000-0002-9364-3579 


\section{REFERENCES}

$1 \mathrm{He} \mathrm{S}$, Craig BA, Xu H, et al. Unmet need for ADL assistance is associated with mortality among older adults with mild disability. $J$ Gerontol A Biol Sci Med Sci 2015;70:1128-32.

$2 \mathrm{Zhu} \mathrm{H}$. Unmet needs in long-term care and their associated factors among the oldest old in China. BMC Geriatr 2015;15:46.

3 Momtaz YA, Hamid TA, Ibrahim R. Unmet needs among disabled elderly Malaysians. Soc Sci Med 2012;75:859-63.

4 Quail JM, Wolfson C, Lippman A. Unmet need for assistance to perform activities of daily living and psychological distress in community-dwelling elderly women. Can J Aging 2011;30:591-602.

5 Depalma G, Xu H, Covinsky KE, et al. Hospital readmission among older adults who return home with unmet need for ADL disability. Gerontologist 2013;53:454-61.

6 Andrade TBde, Andrade FBde. Unmet need for assistance with activities of daily life among older adults in Brazil. Rev Saude Publica 2018;52:75

7 Zeng Y, Feng Q, Hesketh T, et al. Survival, disabilities in activities of daily living, and physical and cognitive functioning among the oldestold in China: a cohort study. Lancet 2017;389:1619-29.

8 Chen N, Li X, Wang J, et al. Rural-Urban differences in the association between disability and body mass index among the oldest-old in China. Arch Gerontol Geriatr 2019;81:98-104.

9 Liang Y, Welmer A-K, Möller J, et al. Trends in disability of instrumental activities of daily living among older Chinese adults, 1997-2006: population based study. BMJ Open 2017;7:e016996.

10 Zhang Q, Wu Y, Liu E. Influencing factors of Undermet care needs of the Chinese disabled oldest old people when their children are both caregivers and older people: a cross-sectional study. Healthcare 2020;8:365-24

11 Desai MM, Lentzner HR, Weeks JD. Unmet need for personal assistance with activities of daily living among older adults. Gerontologist 2001;41:82-8.

12 Zhu Y, Österle A. Rural-Urban disparities in unmet long-term care needs in China: the role of the hukou status. Soc Sci Med 2017;191:30-7.

13 Schure MB, Conte KP, Goins RT. Unmet assistance need among older American Indians: the native elder care study. Gerontologist 2015;55:920-8.

14 Wilkinson-Meyers L, Brown P, McLean C, et al. Met and unmet need for personal assistance among community-dwelling new Zealanders 75 years and over. Health Soc Care Community 2014;22:317-27.

15 Hajian-Tilaki K, Heidari B, Hajian-Tilaki A. Are gender differences in health-related quality of life attributable to sociodemographic characteristics and chronic disease conditions in elderly people? Int J Prev Med 2017;8:95.

16 Maji S. Society and 'good woman': A critical review of gender difference in depression. Int J Soc Psychiatry 2018;64:396-405.

17 Hou C, Ping Z, Yang K, et al. Trends of activities of daily living disability situation and association with chronic conditions among elderly aged 80 years and over in China. J Nutr Health Aging 2018;22:439-45.

18 Katz S, Ford AB, Moskowitz RW, et al. Studies of illness in the aged. The index of ADL: a standardized measure of biological and psychosocial function. JAMA 1963;185:914-9.

19 Ge D, Chu J, Zhou C, et al. Rural-Urban difference in the use of annual physical examination among seniors in Shandong, China: a cross-sectional study. Int J Equity Health 2017;16:86.

20 Chae S, Lee Y, Kim J, et al. Factors associated with perceived unmet dental care needs of older adults. Geriatr Gerontol Int 2017;17:1936-42.

21 Zhou C, Ji C, Chu J, et al. Non-Use of health care service among empty-nest elderly in Shandong, China: a cross-sectional study. BMC Health Serv Res 2015;15:294.

22 Peng X, Song L, Huang J. Determinants of Long-term care services among disabled older adults in China: A quantitative study based on Anderson's behavioral model. Population research 2017;41:46-59.

23 Jiang X, Wei M. Activity of daily living of the Chinese oldes-old and its change between 2002 and 2011. Population \& Development 2015;21.

24 Katz SJ, Kabeto M, Langa KM. Gender disparities in the receipt of home care for elderly people with disability in the United States. JAMA 2000;284:3022-7.

25 Peng R, Wu B, Ling L. Undermet needs for assistance in personal activities of daily living among community-dwelling oldest old in China from 2005 to 2008. Res Aging 2015;37:148-70.

26 Feng Z, Liu C, Guan X, et al. China's rapidly aging population creates policy challenges in shaping a viable long-term care system. Health Aff 2012;31:2764-73.

27 Kajonius PJ, Kazemi A. Safeness and treatment mitigate the effect of loneliness on satisfaction with elderly care. Gerontologist 2016;56:928-36.

28 Boulos C, Salameh P, Barberger-Gateau P. Social isolation and risk for malnutrition among older people. Geriatr Gerontol Int 2017;17:286-94.

29 Ong AD, Uchino BN, Wethington E. Loneliness and health in older adults: a mini-review and synthesis. Gerontology 2016;62:443-9.

$30 \mathrm{Wu}$ X, Treiman DJ. The household registration system and social stratification in China: 1955-1996. Demography 2004;41:363-84.

31 Lawson JE, Cruz RA, Knollman GA. Increasing positive attitudes toward individuals with disabilities through community service learning. Res Dev Disabil 2017;69:1-7.

32 Wu Q, Chow JC-C. Social service utilization, sense of community, family functioning and the mental health of new immigrant women in Hong Kong. Int J Environ Res Public Health 2013;10:1735-46.

33 Campione JR, Zebrak KA. Predictors of unmet need among informal caregivers. J Gerontol B Psychol Sci Soc Sci 2020;75:2181-92.

34 Benedetti TRB, Mazo GZ, Borges LJ. [Health status and physical activity levels among the elderly who are participants and nonparticipants in social welfare groups in Florianópolis]. Cien Saude Colet 2012;17:2087-93. 